\title{
EL CONSEJO NACIONAL DE JUSTICIA
}

\section{(Antecedentes en el Perú y Legislación comparada)}

\section{Antecedentes en el Perú}

Iniciado en los comienzos de la vida republicana del Perú, aún prosigue sin lograr una solución satisfactoria, el esfuerzo de juristas y legisladores por alcanzar un sistema que lleve al Poder Judicial magistrados probos, independientes y capaces.

Las primeras constituciones confirieron a los "Cuerpos electorales", a las "Juntas Departamentales" y a los "Colegios Electorales" la facultad de presentar ante los poderes legislativo y ejecutivo a los candidatos a cargos judiciales.

La Constitución vitalicia de 1826 atribuyó a los "Colegios Electorales" (art. 47\%, inc. 89) la facultad de presentar ante la Cámara de Senadores una lista de postulantes a jueces de distrito. Según la Constitución de 1828 eran las "Juntas Departamentales" - elegidas por los Colegios Electorales de Parroquia y de Provincia- las que sometian al Senado (art. $75^{\circ}$ incs. $170^{\circ}, 10^{\circ}$ y 19\%), listas dobles y ternas dobles para la designación de vocales de la corte suprema, vocales de las cortes superiores y jueces de primera instancia. La Carta de 1834 confiere a los "Colegios Electorales" de provincia de los respectivos departamentos (art. 51\%, inc. 26) la potestad de proponer ante el Congreso la lista de los elegibles para la Corte Suprema. La Constitución liberal de 1856 otorgaba a las "Juntas Departamentales" la facultad de proponer ante el Poder Ejecutivo (art. 1049) los candidatos para la provisión de los cargos de segunda y primera instancia.

En lo que se refiere a las designaciones mismas, de conformidad con la Constitución de 1826, la Cámara de Senadores elegia a los jueces de distrito y a los subalternos de todo el departamento de justicia (art. 47\%, inc. 8\%) y la Cámara de Censores "a los individuos que deben formar el Tribunal Supremo" (art. $60^{\circ}$, inc. 19) de la lista enviada por el Poder Ejecutivo (art. $80^{\circ}$, inc. 25\%) que se originaba en una propuesta de la Cámara de Senadores (art. 47\%, inc. 69). El Poder Ejecutivo según la Constitución de 1828, tenia la potestad de realizar todas las designaciones judiciales, a propuesta en terna doble del Senado, las de la Corte Suprema, y a propuesta en terna de las cortes respectivas, a los demás (art. 90\%, inc. 209). La Constitución de 1834 reveló una tendencia exageradamente parlamentarista. Los nombramientos judiciales se hacian: los de primera instancia por la Cámara de Diputados (art. 24\%) los de segunda instancia por la de Senadores (art. 34\%) y los de la Corte Suprema por el Congreso en pleno (art. 519, inc. 26\%). La Constitución autoritaria de 1839 fue eminentemente presidencialista: el Presidente de la República designaba a todos los integrantes del Poder Judicial y podía suspenderlos hasta por 4 meses, trasladarlos y remover a los vocales de la Corte Suprema, a los de las cortes superiores y a los jueces de primera instancia con el voto unánime, con los dos tercios y con la mayoria de los miembros del Consejo de Estado, respectivamente (art. $87^{\circ}$, incs. $24^{\circ}, 10^{\circ}$ y $43^{\circ}$ ).

Además de los sistemas de nombramientos esbozados, que menoscababan notoriamenie la independencia de los jueces, desde la dación de la Carta de 1828 hasta el 9 de enero de 1865 en que se estableció el Tribunal Supremo de Responsabilidad Judicial, un organismo de origen político nominado Tribunal de Slete jueces, tenia las facultades de conocer las acciones de responsabilidad contra la Corte Suprema, contra alguno de sus miembros y resolver los recursos de nulidad que se interpusieran contra las sentencias que pronunciaba en última instancia.

La Constitución de 1828 (art. 112\%) disponia que el citado Tribunal fuera elegido por el Congreso cada bienio, mediante sorteo dentro de un número doble de 
letrados que no pertenezcan a él. El Consejo de Estado, según la Carta de 1834 (art. 101, inc. 6ㅇ) designaba a los miembros del mencionado Tribunal entre sus integrantes "pudiendo recaer la elección de tres individuos que no sean de su seno", sistema que mantiene la de 1839 (art. 103\%, inc. 5\%) sin señalar que deben ser miembros del Consejo.

A partir de la Constitución de 1856 en que se inició el nuevo sistema de designaciones éste ha subsistido hasta 1970. Según la carta liberal la nominación de los integrantes de la Corte Suprema correspondía al Congreso a propuesta en terna doble del Poder Ejecutivo y los de las cortes superiores y jueces de primera instancia a éste último a propuesta en terna doble de las juntas departamentales (art. 127\%). La Constitución de 1860 (art. 126\%) reemplazó las ternas dobles de las juntas departamentales por ternas dobles de las respectivas cortes. La de 1920 arts. $147^{\circ}$ y $148^{\circ}$ ) estableció la propuesta por el Poder Ejecutivo ante el Congreso en decenas para los cargos de la Corte Suprema y en el resto mantuvo el mismo procedimiento reproducido por la Constitución promulgada en 1933 (arts. 222 ${ }^{\circ}$ y 223).

Es interesante anotar que la Constitución de 1867 (que no alcanzó vigencia) señala que la designación de magistrados de la Corte Suprema debe hacerse por el Congreso de una lista que aquella le presente formada por todos los magistrados con más de 15 años de servicios y todos los abogados con más de 20 años con estudio abierto; la designación de los magistrados de segunda instancia también por el Congreso de una terna doble formada por la Corte Suprema "la una con Magistrados con 10 años de servicios y la otra con abogados con 10 años de estudio abierto". Los jueces de derecho debian ser nombrados por la Corte Suprema a propuesta en terna doble de la Corte Superior respectiva (art. 127\%). La importancia de este sistema que, lamentablemente no llegó a realizarse, se halla en la ingerencia que atribuye a la Corte Suprema, y en su apertura a todos los magistrados y abogados que señala.

Surgida la crisis política de 1930 se hizo patente, una vez más, la necesidad de reformar el régimen de designaciones judiciales, con el propósito de eliminar la influencia de los Poderes Legislativos y Ejecutivo.

Los proyectos que se elaboran, recogen y cristalizan la idea de formar una asamblea independiente, inte- grada por personas de la más alta calidad, representativas del propio Poder Judicial, de las facultades de derecho, de los colegios de abogados, que tuviera como misión preparar las listas de candidatos en unos casos, y nombrar en otros, a los integrantes de la magistratura.

Por primera vez y por encargo del gobierno de la época, el Colegio de Abogados de Lima preparó un proyecto fechado el 31 de octubre de 1931 que propone la creación de un "Consejo Nacional de Justicia" presidido por el Ministro de ese Ramo e integrado por los jueces en ejercicio de la Corte Suprema y un delegado designado anualmente por cada una de las facultades de derecho de las universidades nacionales y por cada uno de los colegios de abogados (art. 5\%). El proyecto contempla la creación de Consejos departamentales de Justicia con un presidente, los jueces en ejercicio de la correspondiente corte superior y tres abogados: uno designado anualmente por el Consejo Nacional; el segundo por la Facultad de Derecho del lugar donde funcione el Consejo Departamental o en su defecto del más próximo y el tercero por el Colegio de Abogados (art. 69). Los jueces de la Corte Suprema serían elegidos por las Cámaras reunidas a propuesta de tantos candidatos como cortes superiores, hecha por el Consejo Nacional de Justicia que para una tercera vacante debia proponer una decena de abogados (art. $7^{\circ}$ ). Los jueces de las cortes superiores debian ser elegidos por el propio Consejo de dos ternas: una presentada por la Corte Suprema y la otra por el respectivo Consejo Departamental de Justicia (art. $8{ }^{\circ}$ ) y los jueces de primera instancia por el Consejo $\mathrm{Na}$ cional de acuerdo con la propuesta que formule el Consejo Departamental "a mérito de los concursos que se verificarán ante ellos en la forma que determine la ley" (art. 9\%).

El régimen referido reunia los caracteres de una cooptación atenuada. El Consejo de Justicia al que se atribuia la presentación ante el Congreso de las listas de candidatos a las judicaturas de la Corte Suprema y la designación de los magistrados de primera y segunda instancia debia estar integrado por los miembros de dicha Corte. Además, la constitución de Consejos Departamentales significaba un intento de vencer la tendencia centralista de las designaciones jurídicas.

Con fecha 5 de diciembre de 1931, la Comisión que presidió el ilustre jurista Doctor Manuel Vicente Vi- 
llarán envió al gobierno el ante-proyecto de Constitución que le había encomendado.

En la Exposición de Motivos se señala que el Poder Judicial como "gran dirimente de los conflictos jurídicos entre los particulares" y "protector del ciudadano contra los excesos injustos de la autoridad" debe ser "totalmente independiente".

Tal independencia podía lograrse, a juicio de la Comisión, apartando al Poder Ejecutivo de los nombramientos para los cargos de la Corte Suprema encomendándolos al Senado a propuesta del Consejo de Justicia "representativo del foro nacional" y de la misma Corte Suprema, los de segunda instancia al Consejo Nacional citado a propuesta en dos ternas de la Corte Suprema y del Consejo Regional respectivo, y los de primera instancia a propuesta en terna doble de la Corte Superior ante la Junta Directiva del Consejo Regional (art. 138).

El Consejo de Justicia debía estar integrado por el Decano y los ex-Decanos de la Facultad de Derecho de la Universidad de San Marcos y del Colegio de Abogados de Lima y por un abogado designado por cada una de las demás facultades de derecho de las Universidades Nacionales y los otros colegios de abogados de departamentos que sean sede de Corte Superior (art. 137\%).

Según la Comisión, el Consejo así concebido seria "una Corporación selecta que ofrece las máximas garantías racionales posibles, de proceder con libertad y criterio y con sentido de responsabilidad. En sus votaciones - agregaba- es seguro que ejerza sana influencia el sentido del honor profesional y del prestigio de la carrera, para tratar de que la Corte Suprema, que es su simbolización más encumbrada, sea constituida con las más reconocidas eminencias".

Los autores de la Constitución de 1933 siguieron la corriente politica de la Carta anterior. Sus arts. 222 y 223 atribuyen al Congreso y al Poder Ejecutivo la potestad de realizar los nombramientos judiciales. Sólo los de los jueces de paz — según la ley de la materia- correspondían al Poder Judicial.

El Dr. Diómedes Arias Schreiber, que ejerciera el Decanato del Colegio de Abogados de Lima, en 1931 en que dicha institución elaboró el proyecto citado antes, en el libro "Derecho Procesal Civil" publicado en 1932, reitera los lineamientos generales del mismo.

La Comisión Organizadora del Congreso Internacional de Juristas que se realizó en Lima durante el mes de diciembre de 1951 con motivo del IV Centenario de la Universidad Nacional de San Marcos, consideró dentro del temario de dicho certamen, entre las materias de Derecho Constitucional, el tema que tituló "Mejor sistema de provisión de cargos del Poder Judicial".

El Colegio de Abogados de Lima presentó una ponencia redactada por los doctores Roberto Neves V., Luis Quiñe Arista y José Pareja Paz Soldán.

La citada ponencia resume la legislación extranjera dictad a hasta esa época, menciona los antecedentes nacionales antes referidos y señala además que el Doctor Manuel J. Bustamante de la Fuente presentó al Senado en 1945 un proyecto referente al Consejo Nacional de Justicia "que designaría a los miembros del Tribunal Supremo y establecería un sistema de turnos y rotaciones para la provisión de las diferentes vacantes". La misma ponencia recuerda que "En 1948, Luis Quiñe Arista en "La reforma de la organización judicial peruana" recogió el contenido esencial del proyecto Bustamante, conformándolo con el sistema de concurso para la provisión de los cargos judiciales de primera instancia".

Según el Colegio de Abogados de Lima el Consejo Nacional de Justicia debía ser presidido por el Ministro de ese ramo y estar integrado por cinco magistrados de la Corte Suprema, dos delegados de las corporaciones de abogados debiendo ser uno de ellos del Colegio de Abogados de Lima y el otro de los demás Colegios de Abogados, un delegado de la Facultad de Derecho de la Universidad Mayor de San Marcos, designado entre sus profesores titulares con más de 15 años de servicios docentes y finalmente, otro delegado de las demás Facultades de Derecho de la República.

Los magistrados de la Corte Suprema debían ser elegidos, según la ponencia antedicha, por el Consejo Nacional de Justicia; los magistrados de segunda instancia por la Corte Suprema en tres turnos: el primero en concepto de ascenso por rigurosa antigüedad en la categoría inferior; el segundo, mediante concurso de méritos entre magistrados de la categoría inferior y el tercero, también por concurso entre abogados "con ejercicios técnicos y prácticos". Los magistrados de primera instancia serían designados por la Corte Suprema a propuesta en una terna formada mediante concurso por la respectiva Corte Superior. El nombramiento de los jueces de paz letrados, que realizarian las cortes superiores mediante concurso, requería la aprobación de la Corte Suprema. 
En lo que se refiere a la duración y a los poderes del Consejo Nacional de Justicia, se señala en la ponencia que dicho Consejo "debe inegrarse como en Cuba, cada vez que haya que hacer una elección; ello además eliminaría la duradera influencia que pudieran tener los miembros del mismo sobre los magistrados".

En 1956, como representante parlamentario presenté a la Cámara de Diputados, un proyecto de reforma constitucional de los artículos 222 y 223 de la Carta promulgada en 1933.

Propuse que la designación de los magistrados de la Corte Suprema se hiciera por el Consejo de Justicia, que la de los de segunda instancia se efectuara por dicho organismo a propuesta en terna doble de la Corte Suprema y la de los de primera instancia por dicha Corte a propuesta también en terna doble de la corte superior respecilva que debía seleccionar a los candidatos a través de un concurso de aptitudes.

Según este proyecto, el Consejo de Justicia debía ser presidido por el Ministro de ese Ramo e integrado por seis delegados de la Corte Suprema elegidos entre magistrados jubilados y fiscales suplentes; seis del Poder Legislativo, entre áoogados con más de veinte años de ejercicio profesional; tres elegidos por las facultades de Derecho de las Universidades Nacionales entre sus profesores con más de diez años de servicios docentes, y tres por los Colegios de Abogados, entre profesionales con más de 20 años de ejercicio.

El Consejo de Justicia, que tiene como misión esencial designar a los integrantes del más alto cuerpo de un poder del Esiado, según el proyecto, se integraria según él, por delegados de quienes han recibido el mandato popular y del propio Poder Judicial, por una parte; y de las entidades que representan a la profesión forense, por otra. El Consejo realizaria los nombramientos de la Corle Suprema; y los de segunda instancia a propuesta de la misma. Los de primera instancia corresponderían a la Corte Suprema a propuesta de las cortes superiores, que actuarian en vez de los consejos regionales considerados en otros proyectos.

La ley No 13036 de 24 de noviembre de 1958, encargó a una Comisión el estudio de la reforma del Poder Judicial y la formulación del correspondiente proyecto de ley.

La Comisión formada de acuerdo con la referida ley consideró de necesidad la modificación del sistema de designaciones judiciales sustentando en los arts. 222\% y 223 ? de la Constitución y propuso su reforma a través de dos proyectos formulados por sus miembros que no coincidieron en una fórmula que representara la unanimidad de sus opiniones.

Según el proyecto Nọ 3-A de los doctores León Barandiarán, Eguren y Sánchez Palacios, los magistrados judiciales de la Corte Suprema deben ser nombrados por resolución del Presidente de la República refrendada por el Ministro del Ramo a propuesta en terna del Consejo Nacional de la Magistratura (art. $19)$, los de las cortes superiores a propuesta en terna de la Corie Suprema (para el Dr. León Barandiarán a propuesta en dos ternas, correspondiendo la otra a la Federación Nacional de Colegios de Abogados) (art. 2\%), los de primera instancia a propuesta en dos ternas: una de la Corte Superior y la otra del Colegio de Abogados respectivo, y a falta de éste las dos ternas de la Corte Superior (art. 3\%) las entidades "llamadas a formular las propuestas en todas las escalas judiciales tendrán forzosamente en cuenta los datos del Cuadro de Antigüedad y Méritos de los candidatos de la carrera" (art. 4\%). El Consejo Nacional de la magistratura debe estar integrado por el Presidente de la Corte Suprema que lo presidirá; tres miembros de dicha Corte designados por ella; tres Decanos o ex-Decanos de los Colegios de Abogados, elegidos por todos estos; tres representantes de las Facultades de Derecho de las Universidades Nacionales elegidos entre sus Decanos o profesores con más de 15 años de servicios en la respectiva Facultad (art. 6\%). Los miembros del Consejo Nacional de la Magistratura -excepto su Presidente- - se renovarán cada tres años (art. 69).

El Dr. León Barandiarán consideró que en el referido consejo deberian incluirse un representante del Senado de la República y otro de la Gámara de Diputados, elegidos por la respectiva rama del Parlamento; que la elección de los Decanos o ex-Decanos de los Colegios de Abogados se haga por los Decanos de los mismos y que los delegados de las Facultades de Derecho sean dos, que reunan los mismos requisitos señalados anteriormente.

Los miembros de la Comisión Drs. Bustamante Rivero, Cisneros, Zárate Polo y en parte el Dr. Ramírez Otárola, que se adhirió al anterior proyecto en lo que atañe a la designación de magistrados de la Corte Suprema y a la composición del Consejo Nacional de la Magistratura, formularon el proyecto No 3-B. 
Este proyecto considera que el Consejo Nacional de Justicia debe realizar el nombramiento de los magistrados de la Corte Suprema a propuesta en terna simple de la Corte Supiema y propuesías unipersonales de cada una de las Cortes Superiores y de cada uno de los colegios de abogados (art. 1\%), de los magistrados de segunda instancia a propuesta de ternas simples de la Corte Suprema, de la Corte Superior y del Colegio de Abogados respectivos (art. $2^{\circ}$ ) y el de los de primera instancia por la Corte Suprema a propuesta en ternas simples presentadas separadamente por la Corte Superior y por el Colegio de Abogados (art. 3 ). Para la formulación de las propuestas se tendrá en cuenta el cuadro de antigüedad y méritos de los magistrados y "la reputación moral y profesional" de los abogados (art. 4\%). El Consejo Nacional de Justicia, se integrará según este proyecto, por tres miembros activos o jubilados de la Corte Suprema elegidos por ella; tres abogados con más de veinte años de ejercicio profesional elegidos por la Corte Suprema a propuesta en ternas simples por cada uno de los colegios de abogados; tres profesores de derecho designados también por la Corte Suprema a propuesta en ternas simples por el Consejo de la Facultad de Derecho de cada universidad nacional entre sus docentes con más de 20 años de servicios. Los miembros del consejo desempeñarán el cargo por seis años y serán renovables por tercios cada dos años. "La función de Consejero es obligatoria y gratuita" (art. 5\%). El Dr. Ramírez Otárola se adhirió a los artículos $2^{\circ}$ y $3^{\circ}$ del proyecto.

No habiéndose realizado la reforma constitucional, el anteproyecto que formuló la Comisión establecida por mandato de la ley № 13036, mantuvo el sistema vigente de designaciones judiciales.

La Comisión revisora creada por resolución suprema de 7 de mayo de 1963 pudo introducir algunas modificaciones importantes en el proyecio que fueron incorporadas a los arts. $48^{\circ}, 49^{\circ}$ y $50^{\circ}$ de la ley.

Dichas normas preceptuan que el Poder Ejecutivo formulará las decenas que debe someter ante el Congreso para la designación de magistrados de la Corte Suprema con los nombres de ocho vocales y fiscales de cortes superiores elegidos entre los 16 que ocupen los primeros puestos en los cuadros de antigüedad y méritos y los de dos abogados elegidos entre 5 que le presente la Corte Suprema. Se señala que las ternas que formule la Corte Suprema para la provisión de los cargos de segunda instancia serán integradas por 4 miembros del Poder Judicial que ocupen los 10 primeros puestos en los cuadros respectivos de antigüedad y méritos y dos abogados seleccionados entre 4 que presente la Corte Superior respectiva. La ley preceptúa, asinismo, que las ternas para la designación de funcionarios de primera instancia podrán comprender a magistrados del mismo grado y deberán incluir en todo caso, dos abogados y un juez de paz letrado y que "gozarán de preferencia los que hayan aprobado los respectivos cursos de especialidad en las Facultades de Derecho".

La Comisión Revisora buscó limitar, con las innovaciones que introdujo, la amplitud de la potestad de formular decenas y ternas en orden a la inclusión de magistrados calificados y abogados cuidadosamente elegidos.

Después de una larga y apasionada polémica el Congreso de la República por ley № 15076 de 22 de junio de 1964 y su aclaratoria № 15115 de 24 de julio de ese año, modíficó los arts. $48^{\circ}, 49^{\circ}$ y $50^{\circ}$ de las Ley Orgánica del Poder Judicial antes resumidos.

Dicha ley dispone que para formular las decenas, el Poder Ejecutivo elegirá entre los 40 magistrados de segunda instancia que ocupen los 20 primeros puestos en cada uno de los cuadros de antigüedad y méritos y entre 15 abogados presentados en grupos de 5 por la Corte Suprema, la Federación Nacional de Colegios de Abogados (que carecía de personeria jurídica en esa época) y el Colegio de Abogados de Lima. La misma Ley preceptúa que las ternas para proveer cargos de segunda instancia comprenderán dos abogados seleccionados en dos grupos de cuatro por la corte superior y el colegio de abogados correspondiente, si lo hubiere; y que para las ternas atinentes a primera instancia, la corte superior designará cuando menos un abogado de los tres que proponga el respectivo colegio si lo hubiere.

La ley mantuvo el mismo criterio de la Comisión Revisora, aunque amplió el sistema de las propuestas. Es curioso señalar que el punto central del debate insistió en que no fueran los 10 primeros sino los 40 primeros de segunda instancia para la formulación de las decenas.

Los Congresos que realizó la Federación Nacional de Colegios de Abogados -en Lima, Trujillo, Arequipa y Piura- y el segundo Congreso de Abogados del Centro que tuvo lugar en Huancayo, reiteraron la posición del Foro del País favorable a la adopción de 
un sistema de designaciones que garantice la independencia de los jueces.

Las dos Conferencias nacionales de decanos de Colegios de Abogados convocadas y realizadas bajo los auspicios del Colegio de Abogados de Lima del 6 al 6 de marzo de 1567 y del 26 al 30 de octubre de ese año, insistieron en la necesidad de reformar el sistema de designaciones judiciales y en la creación de un Consejo Nacional de Justicia.

El V Congreso de Abogados realizado en el Cuzco, en su sesión plenaria de 23 de enero de 1968, aprobó como resolución solicitar al Poder Legislativo la reforma "perentoria" de los arts. 222\% y 223 de la Constitución; que la provisión de todos los cargos judiciales se efectúe a base de concurso de méritos y aptitudes; que se faculte al poder judicial para elaborar y ejecutar su presupuesto funcional y que la reforma constitucional propuesta contemple la creación del Consejo Nacional de Justicia, organismo autónomo encargado de los nombramientos judiciales por elección e integrado en tercios por representantes del Poder Judicial, de las Facultades de Derecho, de las Universidades Nacionales y de la Federación de Colegios de Abogados del Perú.

Del 26 al 31 de enero de 1969, fue convocado por la Federación Nacional de Colegios de Abogados un Congreso Nacional Extraordinario en el Callao, cuyo temario, en su párrafo Décimo cuarto comprende: El Consejo Nacional de Justicia y las designaciones judiciales $_{1}$

El Dr. José León Barandiarán presentó a dicho certamen una ponencia en la que proponia la creación del Tribunal de control de la constitucionalidad y de la legalidad y de nombramientos judiciales.

El citado tribunal, según la propuesta, debería estar formado por dos magistrados jubilados o cesantes de la Corte Suprema designados por esta; dos decanos o ex-decanos de las Facultades de Derecho de la República designados por el Consejo Interuniversitario; un ex-decano del Colegio de Abogados de Lima nominado por esta Institución; dos miembros de la Academia Peruana de Derecho designados entre sus integrantes, y dos miembros designados por sorteo entre los que propusieran las cortes superiores y los colegios de abogados, a excepción del de Lima, respectivamente.

Los nombramientos de primera instancia, de acuerdo con la ponencia, serian hechos por el Tribunal a base de concursos de méritos entre los postulantes; los nombramientos de segunda instancia serán hechos por el Tribunal debiendo ser cubiertas las tres primeras vacantes por funcionarios de primera instancia; la cuarta por profesores de derecho o miembros de la Academia Peruana de Derecho y la quinta por un abogado y asi sucesivamente.

Las propuestas serían hechas por la Corte Suprema que presentará nueve magistrados cuando las vacantes correspondan a estos; por dos facultades de derecho, por sistema de rotación, que propondrán tres profesores de derecho cada una en el caso en que el nombramiento corresponda a docentes de derecho; por la Academia Peruana de Derecho que propondrá a tres de sus miembros en su caso; y por la Federación Nacional de Colegios de Abogados que propondrá tres abogados, el Colegio de Abogados de Lima dos abogados y dos de los demás colegios, rotativamente, que propondrán dos abogados cada uno de ellos.

En las designaciones de los magistrados de la Corte Suprema las vacantes se cubrirán también en los mismos cinco turnos por nombramiento del Tribunal. La Corte Suprema propondría nueve magistrados de segunda instancia cuando las vacantes correspondieran a éstos. El Consejo Interuniversitario propondría seis candidatos y la Academia Peruana de Derecho tres cuando les correspondiera la vacante; y la Federación de Colegios de Abogados, el Colegio de Abogados de Lima y dos colegios de abogados que no sean el de Lima, por turnos, propondrían tres nombres la primera y dos una de las otras, cuando la vacante corresponda a un abogado.

De la relación de proyectos que precede, se desprende que ha sido anhelo casi permanente de juristas, legisladores y abogados, la constitución de un organismo cuya autonomía se sustenta en la calidad moral y profesional de sus integrantes, que realice la tarea delicada de nombrar a quienes deben administrar justicia que es el sustento y el valor más alto que inspira a una sociedad democrática.

Casi todos los proyectos coinciden en notas esenciales que atañen a la composición y a las funciones del organismo propuesto. Casi todos consideran que debe estar integrado por miembros o representantes de la Corte Suprema o por delegados designados por ésta. En todos se da participación a las Facultades de Derecho de las Universidades Nacionales, lo que significa la alta consideración que merecieron a sus autores, $y$, del mismo modo, a los Colegios de Abogados. En al- 
gunos de los proyectos se propone la presidencia del entonces Ministro de Justicia y en otros la integración del Consejo por delegados o miembros del Poder legislativo.

La creación de Consejos departamentales de Justicia comprendida en los proyectos de 1931, no aparece en los siguientes.

En lo que se refiere a las designaciones, algunos proyectos atribuyen al Consejo la potestad de nombrar directamente a los miembros de la Corte Suprema y otros a los demás magistrados; otros limitan tal potestad sólo a la Corte Suprema y otros a proponer tales designaciones.

Un examen desapasionado y desinteresado de los antecedentes recogidos, puede llevar a elaborar una adecuada legislación con el propósito de buscar independencia del Poder Judicial frente a cualquier otro organismos extraño a El.

\section{Legislación comparada}

En nuestra época, ha escrito el eminente magistrado español Dr. Castán Tobeñas, cuyo pensamiento mantiene plena vigencia, están en pugna dos principios o sistemas opuestos: el de la "justicia popular" y el de la "justicia técnica". El primero somete las designaciones judiciales a los poderes legislativo y ejecutivo para hacer de los jueces voceros o agentes de la ideología política en boga, mientras que el segundo busca a través de la magistratura lo que éste debe realizar: una justicia imparcial y serena.

La legislación de algunos países ha esbozado o ha establecido instituciones y formas en orden a un método adecuado de nombramientos de los integrantes de la magistratura.

La Constitución republicana española del año 1931 establecía en su artículo 96 una Asamblea con la atribución de proponer ante el Presidente de la República al Presidente del Tribunal Supremo.

La Constitución de Cuba, promulgada el 5 de julio de 1940, preceptúa en su art. 180, que los miembros del Tribunal Supremo serán nombrados por el Presidente de la República a propuesta en forma de un Colegio Electoral.

El Colegio Electoral formado por nueve miembros estaba compuesto por cuatro magistrados del Tribunal Su- premo designados por éste; tres por el Presidente de la República y dos por la Facultad de Derecho de la Universidad de la Habana que no debían pertenecer a la misma, todos con los mismos requisitos exigidos para ser Magistrado del citado Tribunal Supremo.

La citada norma agrega que: "El colegio se forma para cada designación, y sus componentes que no sean magistrados no podrán volver a formar parte del mismo sino transcurridos cuatro años".

La misma Constitución dispone en su art. 181 que "Ios nombramientos, ascensos, traslados, permutas, suspensiones, correcciones, jubilaciones, licencias y supresiones de plazas" se harán por la Sala de Gobierno del Tribunal Supremo formada por el Presidente $y$ seis miembros de éste que no podrán formar parte de dicha Sala dos años sucesivos.

La Carta comentada instituye la carrera judicial y dispone que el ingreso a la misma se hará mediante ejercicios de oposición de los que se exceptúa a los magistrados del Tribunal Supremo (art. 175). Se señala que los nombramientos de Magistrados de Audiencia se harán en tres turnos: el primero por rigurosa antigüedad en la categoría inferior; el segundo por concurso también entre los de la categoría inferior y el tercero por oposición a la que podrán concurrir funcionarios judiciales y abogados siempre que sean menores de 60 años (art. 176). Los nombramientos de jueces se realizaban, de acuerdo con dicha Carta, en dos turnos por antigüedad entre los de la categoría inferior -o por traslado- el primero y por concurso el segundo (art. 177).

El artículo 178, encarga a la Sala de Gobierno del Tribunal Supremo determinar, clasificar y publicar los méritos de los funcionarios judiciales de cada categoría para el turno de ascenso.

En Francia, el propósito de establecer un sistema de designaciones judiciales independientes de las corrientes politicas dominantes se acentuó después de la primera guerra mundial pero no pudo cristalizarse en una fórmula legislativa sino hasta el primer proyecto de Constitución en 1946.

En el proyecto de Constitución aprobado por la Constituyente el 19 de abril de 1946 y rechazado por el pueblo en el referendum de 5 de mayo de ese año, se propone un "Consejo superior de la magistratura" complesto de doce miembros: el Presidente de la República que lo debía presidir; el Guarda sellos, Ministro de Justicia; seis personalidades, elegidas por la 
Asamblea Nacional, fuera de sus miembros, por mayoría de dos tercios y por seis años, debiendo elegir seis suplentes en las mismas condiciones; y cuatro magistrados elegidos también por seis años, uno por el Presidente y los consejeros de la Corte de Casación; otro por los presidentes y consejeros de las cortes de apelación; otro por los presidenies y jueces de los tribunales de primera instancia y el último por los jueces de paz. Cuatro suplentes de los magistrados se eligirian en la misma forma (art. 111). "El Presidente de la República nombra en Consejo superior de la magistratura los magistrados, excluyendo los del parquet" dice el art. 112 y agrega que el Consejo "asegura, en las mismas condiciones y conforme a la ley, la disciplina de tales magistrados, su independencia y la administración de los tribunales judiciales". Se proponia asimismo que el Consejo ejerciera el derecho de gracia (art. 113\%).

Aprobado por una segunda Constituyente el nuevo proyecto de Constitución el 28 de seliembre de 1946 fue sancionado por el referendum de 13 de octubre de ese año y se convirtió en la Carta de 1946.

El artículo 83 de la Constitución mantiene la estructura del proyecto anterior pero eleva de 12 a 14 el número de miembros del Consejo superior de la magistratura, agregando a los mencionados antes "dos miembros designados por seis años por el Presidente de la República que no pertenezcan ni al Parlamento ni a la magistratura, pero que se hallen dentro de las profesiones judiciales, y dos suplenies que reunan las mismas condiciones".

El art. 84 de la Constitución modifica sustancialmente la norma contenida en el $\mathbf{1 1 2}$ del proyecto rechazado. Dicho artículo precisa que "El Presideníe de la República nombra, a piesentación del Consejo superior de la magistratura, los magistrados, a excepción de los del parquet".

Se mantiene la atribución del Consejo de asegurar conforme a ley la disciplina de dichos magistrados, su independencia y la administración de los tribunales judiciales. Se agrega que los magistrados de sitio (jueces a diferencia de los miembros del ministerio fiscal) son inamovibles. Se suprime la atribución del Consejo de ejercer el derecho de gracia.

La agitada vida política de la IV República y la crisis de Argelia que llevaron a investir un gobierno presidido por el general De Gaulle, y a la preparación de un proyecto de Constitución -el de la $\mathrm{V}$
República- aprobado por el referendum de 28 de setiembre de 1958.

El carácter autoritario de esta Constitución y el reforzamiento del Poder Ejecutivo -que constituye sin duda el legado político más importante del general De Gaulle- se refleja también en el título VIII que se denomina "De la autoridad judicial" (el de la constitución de 1946 y en el proyecto se denominaba "Del Consejo superior de la magistratura").

Según el art. 65 de la Constitución de 1958 el Consejo superior de la magistratura "es presidido por el Presidente de la República. El ministro de Justicia es el vice-presidente de derecho. Puede suplir al Presidente de la República. El Consejo superior de la magistratura comprende además nueve miembros designados por el Presidente de la República en las condiciones fijadas por una ley orgánica".

De acuerdo con el precepto transcrito la designación del Consejo obedece a los designios del Poder Ejecutivo.

En cuanto a los nombramientos de los magistrados de sitio, la nueva Constitución limita la potestad del Consejo superior de la magistratura que queda circunscrito a "formular las proposiciones para la nominación de los magistrados de sitio de la Corte de cesación y para las de primer presidente de corte de apelación". En los demás casos solamente "da su opinión en las condiciones fijadas por la ley orgánica sobre las proposiciones del ministro de Justicia relativas a las nominaciones de los demás magistrados de sitio". Sobre el derecho de gracia debe ser consultado únicamente.

La función disciplinaria del Consejo superior de la magistratura es mantenida por la Constitución que señala que al ejercerla debe ser presidido por el primer presidente de la Corte de casación.

Mientras la Constitución de 1946 atribuye al Consejo superior de la magistratura la facultad de asegurar "conforme a ley" "la independencia de los magistrados" (art. 84) el art. 64‥ de la Carta de 1958 declara parlamentariamente: "El presidente de la República es garante de la independencia de la autoridad judicial". Agrega, en otro párrafo, que "El es asistido por el Consejo superior de la magistratura".

La ordenanza № 58-1271 de 22 de diciembre de 1958, ley orgánica del Consejo superior de la magistratura, reglamenta la elección de los miembros de dicho organismo, sus derechos y sus funciones. 
De los nueve miembros que nomina el presidente de la República, tres deben ser integrantes de la Corte de casación y entre ellos uno, abogado general y otros tres magistrados de sitio de las cortes y tribunales. "Estos seis miembros, dice el artículo primero de la Ordenanza, son escogidos de una lista formulada por el bureau de la Corie de casación, que llevará para cada una de las categorias un número triple de los cargos a proveer". Otro miembro será un consejero de Estado elegido entre una lista de tres nombres formulada por la asamblea general del Consejo de Estado. Los otros dos miembros serán "dos personalidades que no pertenezcan a la magistratura escogidas en razón de su competencia".

Los miembros del Consejo superior son designados por cuatro años (art. 2\%) y "ninguno puede mientras duren sus funciones en el Consejo Superior, ejercer ni mandato parlamentario, ni las profesiones de abogado o de oficial público o ministerial" (art. 19).

Los miembros del Consejo superior percibirán una "indemnización de funciones (indemnité de fonctions) fijada por reglamento de administración pública, así como, si hay lugar, una indemnización de desplazamiento" "La indemnización de funciones puede ser diferenciada teniendo en cuenta las remuneraciones públicas o privadas percibidas de otra parte por los miembros del Consejo superior". Los magistrados destacados conservan sus haberes a los que se agrega la indemnización.

La ley señala como atribuciones del Concejo: la nominación de magistrados de sitio, el ejercicio de la función disciplinaria y del derecho de gracia.

Las proposiciones que el Consejo somete al Presidente de la República para la nominación de magistrados de la Corte de casación o de primer presidente de corte de apelación, son decretados en base a un informe de un miembro del Consejo. En lo que concierne a las nominaciones de los otros magistrados de "sitio", el Consejo emite su opinión sobre la proposición del ministro de justicia y después de un informe a cargo de uno de sus miembros. El Consejo opina sobre concesión de distínciones honoríficas a los magistrados y "puede ser consultado por el Presidente de la República sobre todas las cuestiones concernientes a la independencia de la magistratura".

La ley orgánica relativa al Estatuto de la Magistratura, ordenanza No 58-1270 de 22 de diciembre de 1958, completada por otras y por la ley orgánica $N^{\circ}$
70-642 de 17 de julio de 1970, establece una comisión de ascenso encargada del cuadro de ascenso. "El cuadro de ascenso es comunicado como opinión al Consejo superior de la magistratura, dice el art. 34, segundo párrafo de la citada ordenanza, en lo que concierne a los magistrados de sitio antes de ser firmado por el Presidente de la República".

El colegio de magistrados, que se constituye de conformidad con el Decreto No 71-257 de 7 de abril de 1971 designa a los miembros de la comisión de ascenso y de la comisión de disciplina del parquet.

Cuando el Consejo Superior de la Magistratura ejerce funciones disciplinarias de los magistrados de sitio, se reune bajo la presidencia del primer presidente de la Corte de casación. El presidente de la República y el ministro de justicia no asisten a las sesiones, prescribe el art. 13 de la Ordenanza No 581271.

El procedimiento disciplinario está sujeto a las normas que señala la ley orgánica $58-1270$, en las secciones 1 y 2 de su Capítulo VII.

Se considera que todo faltamiento por un magistrado a los deberes de su estado, al honor, a la delicadeza y a la dignidad constituyen una falta disciplinaria, que debe apreciarse, cuando se trata de miembros del parquet, teniendo en cuenta su subordinación jerárquica (art. 43). Al margen de toda acción disciplinaria quienes ejercen la presidencia de los tribunales u otras funciones semejantes tienen el poder de formular una advertencia a los magistrados colocados bajo su autoridad.

Las sanciones disciplinarias aplicables a los magistrados son las siguientes. 1. apercibimiento con inscripción en su foja de servicios; 2 . traslado de servicio; 3. retiro de ciertas funciones; 4 . descenso en el escalafón; 5. Retrogradación; 6. Retiro o la admisión a cesar en sus funciones cuando el magistrado no tenga derecho a pensión de retiro; y 7 . La revocación con o sin suspensión de derechos a pensión.

El guarda sellos, ministro de justicia, en base a una información o petición, a propuesta de los jefes jerárquicos de un magistrado y después de comunicar al Consejo superior de la magistratura, puede de urgencia ordenar la suspensión provisional de un magistrado de sitio hasta que se produzca la decisión definitiva de la acción disciplinaria. Dicha medida no priva de sus haberes al suspendido y no debe ser hecha pública. 
El guarda sellos, ministro de justicia, debe denunciar ante el Consejo Superior de la Magistratura los hechos que den motivo a un proceso disciplinario contra los magistrados de sitio (art. 50).

Desde la iniciación del procedimiento, el investigado tiene derecho a que se le comunique el expediente y las piezas de la investigación preliminar si esta procediera (art. 51). El primer presidente de la Corte de casación, en calidad de presidente del consejo de disciplina, encomienda la investigación a un magistrado del mismo, quien puede prohibir al incriminado continuar en el ejercicio de sus funciones, sin que tal medida acarree privación del derecho a sus haberes ni pueda hacerse pública.

Durante la investigación, el magistrado encargado de ella debe hacer notificar la acusación y los testimonios al investigado a través de un funcionario de un rango por to menos igual al de aquél. El incriminado puede hacerse asistir por uno de sus colegas o por un abogado ante el Consejo de Estado, ante la Corte de Casación o inscrito en la Orden. El procedimiento debe ser puesto a disposición del interesado 48 horas antes de cada diligencia, por lo menos.

Terminado el procedimiento o si éste no fuera necesario, el magistrado incriminado debe comparecer en persona ante el Consejo, puede hacerse asistir o hacerse representar, en caso de enfermedad o impedimento reconocido, por una de las personas citadas en el párrafo anterior.

En el día fijado para la citación, después de oir al director de servicios judiciales y después de la lectura del proceso, el magistrado investigado es invitado a proporcionar las explicaciones y medios de defensa sobre los hechos que le son reprochados.

Las sesiones del Consejo de disciplina son a puerta cerrada; su cesión debe ser motivada y no es suceptible de ningún recurso. Debe ser comunicada al magistrado interesado en forma administrativa y produce sus efectos desde el dia de la notificación.

La disciplina de los magistrados del parquet (ministerio fiscal) está normada por la Sección 3 del mismo Capitulo.

La Comisión de disciplina está presidida por el Procurador General de la Corte de Casación e integrada por un consejero y dos abogados generales de la misma y quince miembros del Parquet, tres por cada nivel jerárquico designados por el Colegio de magis- trados. Los miembros de la Comisión ejercen sus funciones durante tres años.

Las denuncias contra los miembros del parquet son presentadas por el guarda sellos, ministro de justicia, ante el procurador general de la Corte de casación. El procedimiento es similar al que corresponde a los magistrados de sitio. En el caso en que la comisión de disciplina opine que no ha existido falta en el ejercicio de las funciones, el guarda sellos no podrá pronunciar sanción sin someterla a una comisión especial cuya decisión se impone al guarda sellos y a la comisión de disciplina, y al Consejo de Estado en caso de recurso contencioso. Si el guarda sellos, ministro de justicia, entiende tomar una sanción más grave que la propuesta por la Comisión de disciplina, envia a esta un proyecto de decisión motivado. La nueva opinión de ésta debe ser registrada en la foja de servicios del magistrado interesado.

La Constitución italiana de 27 de diciembre de 1947 en su Título IV bajo la denominación de "La Magistratura" se ocupa del Poder Judicial y del Consejo Superior de la Magistratura.

El artículo 104 preceptúa que "la Magistratura constituye un organismo autónomo $e$ independiente de todo otro poder" y que el Consejo Superior de la Magistratura estará presidido por el Presidente de la República y que formarán parte de él "por derecho propio" el primer presidente y el procurador generall de la Corte de Casación. Los otros componentes serán elegidos en sus dos tercios por todos los magistrados ordinarios, entre los pertenecientes a las diversas categorias, y el otro tercio, por el Parlamento, en sesión ordinaria, entre profesores de número de la Universidad en materias jurídicas y abogados con quince años de ejercicio.

Los miembros electivos del Consejo duran en el cargo cuatro años y durante ese período no podrán ejercer la profesión ni formar parte del Parlamento ni de los Consejos Regionales.

La Constitución atribuye, en su artículo 105, al Consejo, según las normas de la organización judicial, los nombramientos, asignaciones, traslados, ascensos y medidas disciplinarias relativas a los Magistrados. El artículo 106 dispone que los nombramientos de los Magistrados se harán por concurso, pero señala que se podrá admitir el nombramiento de magistrados honorarios "con todas las funciones atribuidas a un juez" y que por designación del Consejo Superior de la Magistratura podrán ser llamados al cargo profesores univer- 
sitarios en materias jurídicas y abogados con quince años de antigüedad, que estén inscritos en los registros especiales de las jurisdicciones superiores.

La ley No 195 de 24 de marzo de 1958 norma la constitución y el funcionamiento del Consejo Superior de la Magistratura.

La ley citada establece que el Consejo es presidido por el Presidente de la República y compuesto por el primer presidente de la Corte Suprema de Casación, por el Procurador general de la misma, catorce componentes electos por los magistrados ordinarios y siete componentes elegidos por el Parlamento. El vice-presidente debe ser elegido entre los componentes nominados por el Parlamento.

Los miembros de la magistratura que integran el Consejo son: seis de la Corte de Casación, de los cuales dos deben tener oficio directivo, cuatro de las cortes de apelación y cuatro de los tribunales que tengan por lo menos cuatro años de antigüedad en la promoción a la última categoria que ocupen.

Los componentes del Consejo designados por el Parlamento, serán en sesión común de las dos Cámaras, en escrutinio secreto, y con mayoría de tres quintos de la asamblea. Después del segundo escrutinio la mayoria será de tres quintos de votantes.

Los miembros del Consejo superior no son reelegibles para el período siguiente y los designados por el Parlamento no pueden ser inscritos en los padrones profesionales, ni pueden ser titulares de empresas comerciales ni formar parte del consejo de administración de sociedades de dicha índole. No pueden integrar el Consejo parientes ni afines dentro del cuarto grado; y todos los miembros de dicha entidad, aparte del Vice-Presidente, a quien corresponde una asignación mensual, gozan de dietas por sesión o por viaje los que residen fuera de Roma.

En lo que atañe a su funcionamiento, el Consejo está integrado por un Comité de Presidencia, comisiones y la sección disciplinaria.

El Comité de Presidencia, compuesto por el VicePresidente del Consejo e integrado por el primer Presidente de la Corte Suprema de Casación y por el procurador general de la misma, es el encargado de promover la aciividad administrativa de la entidad.

Las Comisiones se constituyen anualmente a propuesta del Comité de Presidencia y son comisiones examinadoras de concurso y comisiones de escrutinio.
Las deliberaciones del Consejo, en lo que se refiere al concurso para proveer los diversos cargos de la magistratura, se realizan en base al informe de la Comisión correspondiente, la que debe proponer asimismo la designación de magistrados para la Corte de Casación por mérito insigne.

El cuadro de méritos derivado del concurso debe publicarse en el Boletín Oficial y los reclamos que pueden presentarse sobre él se hacen dentro del plazo de 30 días, por el Ministro de Justicia o por el interesado. Después del concurso, los nombramientos son acordados por el Ministro de Justicia.

La Comisión de escrutinio es constituida por el Consejo por todo el tiempo de su duración y su atribución es proponer los ascensos por antiguedad, calificar los méritos de los magistrados y señalar quienes son impromovibles. Las decisiones de la Comisión deben ser comunicadas al Ministro, quien puede interponer recurso contra ellas ante el Consejo en pleno, que juzga definitivamente sobre la materia. La Comisión de escrutinio y promoción para los cargos de la Corte de Casación, es presidida por el Primer presidente de ésta y para las cortes de apelación por el Procurador general ante la Corte de Casación.

La sección disciplinaria del Consejo está formada por diez componentes efectivos y cuatro suplentes. Los componentes efectivos son: el Vice-Presidente que la preside, el primer Presidente de la Corte suprema de casación, dos magistrados de la Corte de casación con oficio directivo, dos magistrados de la Corte de $\mathrm{Ca}$ sación (sin ese oficio), uno de corte de apelación, unrs de tribunal y dos miembros electos por el Parlamento. Los cuatro primeros son miembros de derecho; los otros son designados por sorteo.

La acción disciplinaria se promueve por requerimiento del Ministro de Justicia al Procurador general de la Corte Suprema de casación o por este funcionario como representante del Ministerio Público.

En cada caso, el presidente de la Sección disciplinaria y mediante sorteo, forma, con los miembros de aquella, el Colegio de juzgamiento. Contra la resolución de la Sección Disciplinaria procede recurso ante la Sección de unidad civil de la Corte de Casación, que puede ser interpuesto por el Ministro, por el Procurador General o por el inculpado dentro de los sesenta dias de la comunicación del proveímiento disciplinario en copia integral.

La Constitución de Venezuela, que tantos méritos reune, promulgada el 23 de enero de 1961, en el capítulo 
III de su Título VI, preceptúa en su numeral 217: "La ley orgánica respectiva creará el Consejo de la Judicatura, cuya organización y atribuciones fijará con el objeto de asegurar la independencia, eficacia, disciplina y decoro de los Tribunales y de garantizar a los jueces los beneficios de la carrera judicial. En él deberá darse adecuada representación a las otras ramas del Poder Público".

Tales son los sistemas principales adoptados hasta hoy para lograr el mayor acierto posible en la nominación de los integrantes de la magistratura. Tarea aquella delicada y ardua que exige en quienes la ejercen pensar, como enseña el filósofo del derecho, W. Sauer que la función judicial exige "juicio objetivo e imparcial sin consideración de personas, clara visión de los hechos, conocimiento seguro de los hombres, entereza respecto del superior, benevolencia para con el inferior, inhibición de la personalidad, relegándola a segundo término en beneficio de la cosa misma, y, en definitiva, de la colectividad o aun de la misma Humanidad, eliminando toda influencia partidista". 